\title{
Коллективная память о России XX века и ценности разных поколенческих групп
}

\author{
Виктория А. Баранова*, Мария О. Жукова \\ Московский государственный университет им. М.В. Ломоносова, г. Москва, \\ Российская Федерация \\ *E-mail: bva06@mail.ru
}

\begin{abstract}
Аннотация
Введение. Авторами рассматривается актуальность поАХоАа к изучению комлективной памяти с позиций конструкционизма. При изучении комлективной памяти в Аанном исследовании научные залачи направлены на выявление событийного ряда, который конструирует групповые воспоминания, определяя то, что имеет А^я оАной поколенческой группы современного общества большую значимость, чем Аля Аругой. Новизна исследования заключается в выявлении преобладающих ценностей кажАой поколенческой группы и характеристике содержания комлективных воспоминаний о России XX века с учетом веАущих групповых ценностей. Методы. В исследовании применяются методы количественного и качественного анализа: ассоциативная метолика, методика Аля выявления ценностей Ш. Шварца, анкета Аля сравнения России XX века и илеальной России. Выборку исслеАования состави^и респонденты разного возраста из различных регионов России, всего 90 человек.
\end{abstract}

Результаты. Аанный раздел включает описание солержания групповых воспоминаний о России XX века, групповой структуры преоблалающих ценностей, результаты сравнения России XX века с илеальной Россией Аля трех возрастных групп. Солержание воспоминаний о России XX века и результаты сравнения России XX века и илеальной России отражают групповую поколенческую специфрику: солержание представлено различными событиями; Россия представляется как страной, Аалекой от илеала, так и оценивается высоко. При исследовании групповых ценностей выявлено, что А^я кажАой поколенческой группы характерна собственная структура.

ОбсужАение результатов. Анализ воспоминаний о России XX века показал, что их содержание отражает групповую специффику отношения к прошлому. Полученные результаты подтверАили гипотезу о существовании групповых особенностей конструирования комлективных воспоминаний об историческом периоАе, что Аает возможность опреАелять комлективную память как необходимое свойство социальной группы. В исследовании описан феномен «поколенческой сензитивности», проявАяющийся в повышенной чувствительности (восприимчивости) 


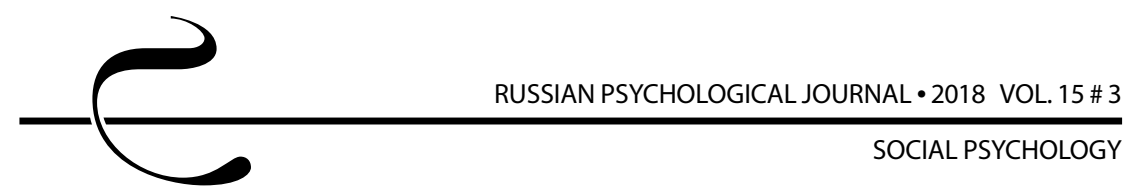

к прошеАшим и происходящим событиям представителей разных социальных поколенческих групп.

\title{
КАючевые слова
}

ко^^ективная память, групповые воспоминания, представления о прош^ом, ценностные ориентации, представления о России, социальные группы, поколенческая сензитивность, межпоколенческие различия, социализация, конструкционизм

\section{Основные положения}

- в рамках социально-психологического подхода изучение колмективной памяти у разных возрастных групп осуществляется в рамках конструкционизма: кол^ективная память отражает групповую специфику отношения к прошлому и яв^яется социально конструируемым френоменом;

- групповая специфика конструирования комлективных воспоминаний актуализирует определенный событийный ряд исторического периода и является результатом особой интерпретации событий прошлого, что определяется интересами, потребностями, ценностями кажАой из рассмотренных социальных (поколенческих) групп; - использование социальной поколенческой группой собственных интерпретационных моделей в отношении прошлого описывается феноменом поколенческой сензитивности, отражающим чувствительность социальной группы к прошлым и происхолящим событиям, особую восприимчивость событий, времени и мира в целом.

\section{Для цитирования}

Баранова В. А., Жукова М.О. Коллективная память о России XX века и ценности разных поколенческих групп // Российский психологический журнал. 2018. Т. 15, № 3. C. 190-208. DOI: 10.21702/rpj.2018.3.9

Материалы статьи получены 29.12.2017

UDC 316.6:316.454.3

DOI: $10.21702 /$ rpj.2018.3.9

\section{Collective Memory of the 20th Century Russia and Values of Different Generational Groups}

\section{Victoria A. Baranova*, Maria O. Zhukova}

Lomonosov Moscow State University, Moscow, Russian Federation

*Corresponding author. E-mail: bva06@mail.ru

\begin{abstract}
Introduction. It is important to consider collective memory from the social constructionism prospective. The present study of collective memory is aimed at identifying the event
\end{abstract}


series that constructs historic memories and determines what is more important to different generational groups of modern society. This paper is the first study on prevailing values in each generational group that characterizes the content of collective memories of the 20th century Russia.

Methods. The study employed quantitative and qualitative methods including (a) associative methods, (b) the Schwartz Value Survey, and (c) the questionnaire for comparing Russia of the 20th century and the 'ideal' Russia. The study sample consisted of 90 respondents of various ages from different regions of Russia.

Results. This section describes the content of group memories about Russia of the 20th century, the specific prevailing group values, and the results of comparing Russia of the 20th century with the 'ideal' Russia in three age groups. After analyzing the content of participants' memories, the authors conclude that various events constitute the content of group memories, reflecting the group specific generational character. In participants' representations Russia appeared to be both a far from an ideal country and a highly appreciated one. The study revealed that each generational group had its own structure of values.

Discussion. The analysis showed that the content of memories about Russia of the 20th century reflected the specific character of relation to the past in the studied groups. The results confirmed the hypothesis about specific group characteristics guiding construction of collective memories of a historical period. This allowed the authors to define collective memory as an essential feature of a social group. The study describes the phenomenon of 'generational sensitivity' that manifests itself as hypersensitivity (impressionability) toward past and current events in representatives of different social generational groups.

\section{Keywords}

collective memory, group memories, representations of past, value guidelines, representations of Russia, social groups, generational sensitivity, intergenerational differences, socialization, constructionism

\section{Highlights}

- The study of collective memory in different age groups is carried out within the constructionism framework of the socio-psychological approach. Collective memory is a socially constructed phenomenon which reflects the specific character of relation to the past within a group.

- Social groups are characterized by their specific ways of constructing collective memories that actualize a certain series of events of a historical period. They result from a special interpretation of the past events, which derives from the interests, needs, and values of each of the social (generational) group considered in the study. 


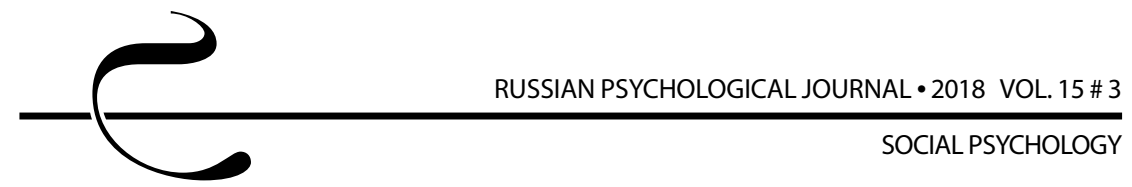

- The phenomenon of generational sensitivity underlies the models of interpreting the past, common to all the members of a social generational group. It reflects sensitivity toward past and current events, time, and the world as a whole among representatives of various social groups.

\section{For citation}

Baranova V.A., Zhukova M.O. Collective Memory of the 20th Century Russia and Values of Different Generational Groups. Rossiiskii psikhologicheskii zhurnal - Russian Psychological Journal, 2018, V. 15, no. 3, pp. 190-208 (in Russian). DOI: 10.21702/rpj.2018.3.9

Original manuscript received 29.12.2017

\section{Введение}

Проблематика коллективной памяти, истории, социального времени являются в настоящий момент времени актуальными и востребованными в различных науках: социологии, антропологии, культурологии, философии, истории. В рамках этих наук формулируется категориальный аппарат исследований памяти, социального времени, феноменов забвения, мобилизации социальной памяти, определяются ее функции, обсуждаются вопросы о том, как работает память, как становится ресурсом социального взаимодействия и культурного выбора [1, 2, 3, 4, 5, 6, 7, 8, 9, 10, 11, 12, 13, 14 и т. д.].

Психологическое осмысление феномена коллективной памяти в современной науке представлено различными направлениями: изучаются представления об исторических персонажах и прошлом России $[15,16,17,18]$, коллективные воспоминания о травматических событиях, преступлениях прошлого, войнах, террористических актах, стихийных бедствиях [19, 20, $21,22,23]$; исследуется влияние коллективной памяти на межгрупповые отношения, политические установки [24]; изучается ее связь с идентичностью $[25,26,27]$.

Большой интерес исследователей направлен на процессы организации памяти, взаимодействия личной памяти и коллективного прошлого, функционирования исторической подструктуры автобиографической памяти [22, $28,29,30,31,32,33,34]$, на выявление специфического содержания различных видов памяти коллективного субъекта (социальная память, культурная память, историческая память, национальная память, мемориальная память и т. п.) [3, 8, 13, 14, 32 и т. д.]. Отдельные аспекты коллективной памяти выявляются в изучении образа России и россиян $[35,36]$.

Тем не менее попытки осмысления феномена коллективной памяти в отечественной социально-психологической традиции являются единичными $[15,17]$. Представленное в данной статье исследование отражает 
социально-психологический ракурс изучения коллективной памяти, целью его является изучение феномена коллективной памяти с позиций социальных групп, что, по нашему мнению, помогает приблизиться к пониманию процесса формирования коллективных воспоминаний, трансляции ценностей и смыслов в обществе между поколениями. Впервые в отечественных социально-психологических исследованиях специфика коллективных воспоминаний рассматривается с учетом групповых ценностей.

\section{Теоретическое обоснование исследования}

М. Хальбвакс определяет коллективную память как коллективный феномен, развивающийся в результате коммуникации, семейных традиций, религиозной и классовой принадлежности. Коллективные воспоминания связаны с историей общества, но история является объективным знанием, а «память всегда является "чьей-то" памятью, обусловлена опытом и интересами какой-либо социальной группы» [28, с. 20].

Вводя понятие коллективной памяти «memoire collective», М. Хальбвакс объясняет, каким именно образом и почему коллективная память становится предметом социального конструирования, как наши представления о прошлом определяются обстоятельствами нашего коллективного настоящего, - «история не просто воспроизводит рассказы современников о событиях прошлого, но время от времени и подправляет их - не только потому, что располагает другими свидетельствами, но и с тем, чтобы приспособить их к приемам мышления и репрезентации прошлого, свойственным нынешним людям» [28, с. 209].

Коллективная память всегда существует в процессе трансформации: т. к. появляются новые интерпретации прошлого, то обществу приходится изменять воспоминания, которые представлены в общественном сознании в связи с необходимостью существования этого общества. А «поскольку мы входим в общество, мы соглашаемся и помнить вместе с ним» [28, с. 216].

В современной науке не существует общей теории коллективной памяти, проблематика коллективной памяти характеризуется многообразием подходов и взглядов на эмпирическое изучение, что проявляется в вариативности предмета исследования и определения коллективной памяти. Понятие «коллективная память» используется как некое общее родовое понятие для близких понятий и явлений общественного сознания, но в каждом конкретном исследовании требуются его дополнительное пояснение и операционализация.

В данном исследовании понятие «коллективная память» используется в понимании М. Хальбвакса и некоторых современных авторов как важнейшая характеристика социальной группы, актуализирующая определенное 
содержание исторических событий как общие для социальной группы, разделяемые людьми «представления об историческом прошлом, которые имеют свойство оживляться, актуализироваться и конструироваться заново в межличностном дискурсе» [16, с. 247].

Отсюда и вытекает предположение о различиях в воспоминаниях об одинаковом историческом периоде и о различной оценке одних и тех же событий у разных поколенческих групп: индивидуальные воспоминания приобретают общее содержание для ее членов, наделяются общими смыслами, становятся совместными представлениями о прошлом, поэтому для разных групп одно и то же событие прошлого может иметь разные смыслы.

В эмпирическом исследовании проверялась гипотеза о существовании групповой специфики коллективных воспоминаний, актуализирующих в памяти определенные исторические события, которая проявляется в различии содержания коллективных воспоминаний о значимых событиях у исследуемых поколенческих групп.

Целью эмпирического исследования, таким образом, являлось выявление особенностей конструирования коллективных воспоминаний об историческом периоде в разных социальных группах и характеристик исследуемых поколенческих групп (ценностей группы).

Коллективная память в данном эмпирическом исследовании изучается через представления о прошлом, которые разделяются членами социальной группы.

Эмпирическое исследование в связи с этим направлено на изучение представлений о России прошлого, XX века, у разных групп, сравнение групповых представлений о России XX века и идеальной России, и выявление ценностей исследуемых поколенческих групп.

\section{Методы}

Для решения поставленных задач использовались ассоциативная методика (прототипического и категориального анализа (П. Вержеса)), методика для выявления структуры ценностей личности Ш. Шварца, анкета для сравнения России XX века и идеальной России, дополненная для этого исследования $[17,36]$.

Для формирования выборки важными являлись критерии возраста и степени социальной активности на данном этапе жизненного цикла, определяемой в соответствии с современными научными взглядами на содержание периода взрослости [37]. Респондентами являлись 90 человек, разделенные по 15 женщин и 15 мужчин в каждую группу (19-34 года (средний возраст - 25,3), 35-60 лет (средний возраст - 49,5), старше 61 года (средний возраст - 73, 2)), все - граждане России, проживающие в городах Калининград, 
Краснодар, Москва, Санкт-Петербург, Петропавловск-Камчатский. Такое разделение позволяет отнести респондентов к поколениям по целому ряду критериев [38], что и дает возможность изучить именно поколенческие аспекты коллективных воспоминаний.

\section{Результаты}

1. В ходе исследования с помощью ассоциативного метода были выявлены особенности представлений о России XX века у представителей разных групn.

У поколенческой группы 19-34 лет образ России XX века представлен различными воспоминаниями, многообразен и не характеризуется единством в оценках событий и персонажей. Респонденты этой группы чаще представителей других поколений вспоминали о событиях Революции 1917 года, В.И. Ленине, о сталинских репрессиях, о И.В. Сталине (оценивая его деятельность негативно), большее внимание уделили техническому прогрессу, холодной войне. Молодое поколение было единственной группой, где назывались как значимые события, связанные с Царской Россией. Содержание образа России XX века составляет, в основном, историческая фактология, которая находится за пределами жизненного опыта респондентов этой возрастной группы.

В коллективной памяти средней поколенческой группы доминируют воспоминания не столько о достижениях и победах нашей страны, сколько о негативной деятельности политических лидеров, их ошибках, а также о кризисах в периоды смен политических и экономических эпох. Представители этой группы чаще других респондентов в своих ответах называют события, связанные с демократизацией и появлением нового государства-Российской Федерации.

Старшая группа (от 61 года) демонстрирует наиболее позитивные представления о России XX века и проявляет тенденцию к идеализации этого временного периода в целом. Для респондентов этой группы Россия XX века ассоциируется с Советским Союзом и достижениями в спорте, науке, культуре, военной и социальной сфере. Эта группа чаще других групп отмечала культурные (балет и литературу) и спортивные достижения (Олимпиаду в г. Москве). В коллективной памяти данной группы значимое место занимают воспоминания о Великой Отечественной войне и ее героях.

\section{2. Для выявления и сравнения представлений о России XX века и идеаль-} ной России респонденты сравнивали между собой Россию XX века и идеальную Россию, оценивая их по 25-ти критериям, с использованием 4-балльной шкалы; для выявления статистической значимости различий использовался 


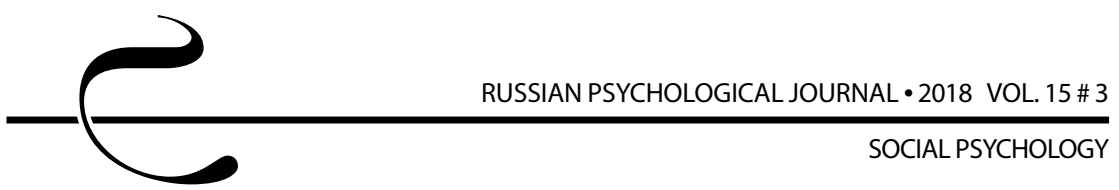

критерий Вилкоксона. Было обнаружено, что оценки России XX века значимо отличаются от идеальной $(p \leq 0,005)$ по многим позициям.

При сравнении России XX века и идеальной России было выявлено, что значимыми результатами для всех возрастных групп является отличие России XX века от идеальной России по следующим позициям: свобода слова $(p \leq 0,0002, p \leq 0,004, p \leq 0,004)$, качество жизни населения $(p \leq 0,0001$, $\mathrm{p} \leq 0,001, \mathrm{p} \leq 0,002)$, организация занятости и комфортных условий проживания пожилых людей и инвалидов ( $p \leq 0,001, p \leq 0,001, p \leq 0,002)$, развитое гражданское общество ( $p \leq 0,0001, p \leq 0,001, p \leq 0,001)$, доверие граждан к полиции ( $p \leq 0,001, p \leq 0,002, p \leq 0,002)$, забота об экологии ( $p \leq 0,000$, $p \leq 0,0001, p \leq 0,001)$. Очевидно, что эти позиции можно категоризировать как актуальные социальные проблемы, составляющие особый дискурс для всего общества.

Результаты также указывают на то, что Россия XX века и идеальная Россия близки по позициям (отсутствуют значимые различия для всех групп): забота власти об интересах государства, сильное мировое влияние, развитая военная сфера, единая национальная идентичность. Эти категории показывают доминирование государства при отсутствии внимания к конкретному человеку.

Для представителей поколения 19-34 лет значимые различия России $\mathrm{XX}$ века и идеальной России получены по 15-ти позициям и включают, кроме вышеназванных, следующие (все отражают потребности конкретного человека): безопасность человека ( $\mathrm{p} \leq 0,0001)$, безопасность государства $(\mathrm{p} \leq 0,001)$, исполнение законов ( $p \leq 0,001)$, свободу личности ( $p \leq 0,0001)$, заботу власти об интересах народа ( $\mathrm{p} \leq 0,001)$, доступное медицинское обслуживание $(p \leq 0,001)$, высокий уровень медицинского обслуживания $(p \leq 0,001)$, высокий уровень коррупции ( $p \leq 0,0001)$, развитие культуры ( $p \leq 0,0002)$.

Для респондентов группы 35-60 лет значимые результаты выявлены по 16-ти позициям (включая 6 общих позиций): безопасность государства ( $p \leq 0,0002)$, исполнение законов $(p \leq 0,001)$, сильные политические лидеры ( $p \leq 0,002)$, свобода личности $(p \leq 0,001)$, забота власти об интересах народа ( $p \leq 0,001)$, единство мнения власти и народа $(p \leq 0,001)$, доступное образование $(p \leq 0,001)$, доступное медицинское обслуживание $(p \leq 0,0001)$, высокий уровень развития медицины $(p \leq 0,0002)$, развитие культурного сектора $(p \leq 0,002)$.

Всё это свидетельствует о том, что представители этих двух групп оценивают Россию прошлого века как страну, достаточно далекую от идеала.

У респондентов в поколенческой группе от 61 года значимые различия выявлены всего по 7-ми критериям (к общим позициям прибавился критерий - уровень преступности $(p \leq 0,004)$, что значительно приближает Россию XX века к идеальной России). Учитывая особенности респондентов 
этой социальной группы, можно предположить: отличия связаны с тем, что эта группа большее время прожила в XX веке и склонна оценивать данный период (события своего детства, молодости, социальную поддержку государства, гордость за достижения Советского Союза и т. п.) значительно выше, позитивнее, и, возможно, в некоторой степени идеализированно.

3. Исследование ценностных ориентаций показало, что существует специфика ценностных ориентаций у представителей разных групп. Наиболее явно среди других ценностей выделяются «доброта», «универсализм», «безопасность» и «самостоятельность».

Таблица 1. Ведущие ценностные ориентации в разных возрастных группах

Table 1. Leading value orientations in different age groups

\begin{tabular}{|l|c|c|c|}
\hline & $19-34$ & $35-60$ & $\begin{array}{c}\text { CTapшe 61 } \\
\text { Over 61 years }\end{array}$ \\
\hline Koброта & $65 \%$ & $65 \%$ & $85 \%$ \\
\hline Самостоятельность & $70 \%$ & $55 \%$ & $15 \%$ \\
Independence & $60 \%$ & $80 \%$ & $85 \%$ \\
\hline Безопасность & $10 \%$ & $45 \%$ & $75 \%$ \\
\hline Safety & & & \\
\hline Универсализм & & & \\
Universalism & & & \\
\hline
\end{tabular}

Для группы 19-34 лет ключевыми ценностями оказались «самостоятельность», в меньшей степени «доброта», и «безопасность». «Самостоятельность» характеризуется самостоятельностью выбора способа действия, независимостью мышления, определяется потребностями индивида в автономности и независимости. При этом ценность «универсализм» как понимание, терпимость, защита благополучия всех людей и природы характерна для очень небольшого количества респондентов этой группы. Эти данные в целом соотносятся с возрастом и активностью ее представителей, их мотивацией достижения, стремлением к независимости, закрепления определенной социальной позиции. 
Для группы от 35 до 60 лет приоритетной является ценность «безопасность», что свидетельствует о важности поддержания стабильности, безопасности, общества, семьи, самого индивида, а также гармонии взаимоотношений. Ценность «универсализм» проявляется у большего количества респондентов, чем в первой возрастной группе, хотя и фиксируется у меньшей половины респондентов данной группы. Как правило, респонденты этой группы-люди, у которых приобретен определенный личный и социальный опыт, они нашли свое место в социуме, поэтому поддержание стабильности и безопасности приоритетно и важно для этой группы.

Для значительного большинства группы старше 61 года характерны ценности «доброта», «безопасность» и «универсализм». Это свидетельствует о важности благополучия близких людей, позитивных личных взаимодействий, безопасности и стабильности общества и гармоничного личного существования в этом мире, а также понимания, терпимости и поддержания благополучия всех людей и природы для этой возрастной группы, о доброжелательности, сфокусированной на благополучии в повседневном взаимодействии с близкими людьми. Очевидно, что приоритет этих ценностей связан с богатым жизненным опытом, мудростью, с глубоким пониманием жизненных смыслов.

\section{Обсуждение результатов}

В результате анализа были выявлены следующие тенденции. В младшей группе, важной характеристикой которой является ценностная ориентация «самостоятельность» (возможность самостоятельно мыслить и выбирать способы действия), содержание коллективных воспоминаний характеризуется большей свободой в оценках и разнообразием упомянутых событий. Воспоминания о России XX века у этой группы разносторонние и представлены широким диапазоном исторической фактологии. Однако у представителей этой группы не наблюдается единства в их оценках этих событий: молодое поколение еще находится в поисках личных смыслов, пытается определить свое собственное отношение к событиям прошлого.

Для большинства респондентов средней поколенческой группы (от 35 до 60 лет), важной характеристикой которой является ценность «безопасность» (поддержание стабильности, безопасности общества, семьи, гармонии самого индивида), содержание коллективных воспоминаний составляют тяжелые события прошлого века - ошибки политических лидеров, реформы, -всё, что связано с деструктивными переменами в жизни общества. В этой группе значительно большее количество респондентов в своих ответах воспроизвели события, связанные с деструктивными процессами периода распада Советского Союза и появления нового государства - Российской Федерации. 
Очевидно, что респонденты этой группы были активными участниками и свидетелями событий «перестройки», «распада СССР», утраты законности, разгула бандитизма, политических, общественных, экономических реформ и связанных с ними трудностей обнищания, негативных переживаний, деструктивных изменений. Эти события составляют содержание трудной жизненной ситуации, которая остается психологической травмой и не преодолена до сегодняшнего дня. Возможно поэтому и ценность безопасности характерна для значительного большинства этой поколенческой группы. В этой группе фиксируется тенденция преобладания негативных оценок актуализируемых событий.

Для группы старшего поколения на первый план выходят такие ценности, как понимание и терпимость, защита благополучия всех людей и природы, потребность в гармонии, стабильности и безопасности. Представители этой группы оценивают Россию XX века как время побед и достижений в различных сферах, как время, комфортное для жизни, что вполне согласуется с выявленными ценностями. Для респондентов этой группы важную роль играют социальные гарантии, стабильность жизни. Ответы свидетельствуют о том, что респонденты идеализируют свое прошлое, оценивая события значительно более высоко и позитивно, чем в остальных группах, - большинство воспоминаний выстроено в положительном акценте. Таким образом, групповые воспоминания о прошлом, несмотря на то, что существует объективная историческая значимость событий этого периода, весьма различны: для младшего поколения - многоплановы, разнообразны и противоречивы, для среднего поколения воспоминания в большей степени негативны и травматичны, в то время как для старшей возрастной группы положительны и идеализированы.

Похожие результаты были получены в исследовании автобиографической памяти, где выявлено, что люди, родившиеся в 1963-1977 гг., чаще включают в свои воспоминания такие деструктивные события, как «перестройка», «путч», «распад СССР», «дефолт», чем люди, родившиеся в 1948-1962 гг. [31]. Значимые межпоколенческие различия проявились в оценках исторических персонажей и современного общества $[16,17]$.

Различия в оценках исторических событий объясняются комплексом причин, важное место среди которых отведено исторической значимости событий, особенностям социализации [16, 39], возрастом накопления максимального объема автобиографической памяти - от 16 до 28 лет [31].

Мы считаем, что для объяснения групповых различий в коллективных воспоминаниях может быть введено понятие «поколенческая сензитивность», которое отражает повышенную чувствительность социальной возрастной группы к прошлым и происходящим событиям, особую восприимчивость 
событий, времени и мира в целом. Индивидуальные воспоминания приобретают в группе общие черты и унифицированное содержание в результате временных и социальных обстоятельств, в которых эта группа существует. Поколенческая сензитивность проявляется в использовании социальной группой особых, собственных интерпретационных моделей отношения к фактам истории, несмотря на существующую объективную оценку определенного периода, что и приводит к избирательности отношения к событиям исторического прошлого. Содержание коллективных воспоминаний у каждой исследуемой поколенческой группы определяется прошлой и актуальной ситуацией ее развития и существования, что и определяет способы конструирования воспоминаний.

Таким образом, результаты, полученные в исследовании, показывают, что коллективные воспоминания о России XX века, интерпретации значимости событий прошлого у участвующих в исследовании групп различны, представлены разными оценками и событиями, как и различны ведущие групповые ценности.

\section{Благодарности}

Статья подготовлена при поддержке РФФИ, проект № 17-06-00980 «Историкополитические факторы трансформации коллективной памяти и идентичности российского общества».

\section{Acknowledgments}

This work was supported by the Russian Foundation for Basic Research for studying Historical and Political Factors of Transformation of Collective Memory and Identity in Russian Society (project no. 17-06-00980).

\section{Литература}

1. Арнаутова Ю. А. Культура воспоминания и история памяти // История и память: Историческая культура Европы до начала Нового времени / отв. ред. Л. П. Репина. М.: Кругъ, 2006. С. 47-55.

2. Трубина Е. Учась вспоминать: векторы исследований памяти // Власть времени: социальные границы памяти / под ред. В.Н. Ярской, Е. Р. ЯрскойСмирновой. М.: ООО «Вариант», 2011. С. 25-44. URL: https://www.hse. ru/pubs/share/direct/document/69748208 (дата обращения: 14.08.2018).

3. Нора П. Проблематика мест памяти // Франция-память. СПб.: Изд-во С.-Петерб. ун-та, 1999. С. 17-50.

4. Савельева И. М., Полетаев А. В. «Историческая память»: к вопросу о границах понятия // Феномен прошлого. М.: Изд-во ГУ-ВШЭ, 2005. C. 170-220. 
5. Зерубавель Я. Динамика коллективной памяти // Империя и нация в зеркале исторической памяти: сборник статей. М.: Новое издательство, 2011. С. 10-29.

6. ОликД. Фигурации памяти: процессо-реляционная методология, иллюстрируемая на примере Германии // Социологическое обозрение. 2012. T. 11, № 1. C. 40-74. URL: https://sociologica.hse.ru/data/2012/06/05/12523 56367/11 1 03.pdf (дата обращения: 14.08.2018).

7. Ярская В.Инверсия времени как механизм памяти в контексте культуры // Власть времени: социальные границы памяти / под ред. В. Н. Ярской, Е. Р. Ярской-Смирновой. М.: ООО «Вариант», 2011. С. 11-24. URL: https:// www.hse.ru/pubs/share/direct/document/69748208 (дата обращения: 14.08.2018).

8. Ассман Я. Культурная память. Письмо, память о прошлом и политическая идентичность в высоких культурах древности / пер. с нем. М. М. Сокольской. М.: Языки славянской культуры, 2004. 368 с.

9. Рикёр П. Память, история, забвение. М.: Издательство гуманитарной литературы, 2004. 728 с.

10. Ассман А. Новое недовольство мемориальной культурой. М.: Новое литературное обозрение, 2016. 232 с.

11. Middleton D., Brown S. D. Issues in the Socio-Cultural Study of Memory //The Cambridge Handbook of Sociocultural Psychology. Cambridge: Cambridge University Press, 2007. P. 661-677. DOI: 10.1017/CBO9780511611162.036

12. Hirst W., Manier D. Towards a psychology of collective memory // Memory. 2008. Vol. 16, Issue 3. P. 183-200. DOI: 10.1080/09658210701811912

13. Репина Л. П. Память и историописание // История и память: Историческая культура Европы до начала Нового времени / отв. ред. Л. П. Репина. М.: Кругъ, 2006. С. 19-47.

14. Люббе Г. Историческая идентичность // Вопросы философии. 1994. № 4. С. 108-113.

15.Емельянова Т. П. Конструирование социальных представлений в условиях трансформации российского общества. М.: Изд-во Института психологии РАН, 2006. 400 с.

16. Емельянова Т. П. Социальные представления: История, теория и эмпирические исследования. М.: Изд-во Института психологии РАН, 2016.476 с.

17. Кузнецова А. В. Коллективные воспоминания о политической власти в различные исторические периоды у представителей разных социальных групп россиян // Социальная психология и общество. 2013. № 3. C. 102-115.

18. Петренко Е., Кожевина Е., Каплун В. Россия. Конец XX века. Представления наших современников // Власть времени: социальные границы памяти / 
под ред. В. Н. Ярской, Е. Р. Ярской-Смирновой. М.: ООО «Вариант», 2011. C. 45-62. URL: https://www.hse.ru/pubs/share/direct/document/69748208 (дата обращения: 14.08.2018).

19. Донцов А. И., Гончарова В. А. Холокост как феномен социальной памяти // Век толерантности. Научно-публицистический вестник. 2005. № 1-2. C. 55-61.

20. Горенштейн Н. И. Восприятие Холокоста современной молодежью // Российский психологический журнал. 2016. Т. 13, № 1. С. 191-199.

21. Evans-Campbell T. Historical Trauma in American Indian/Native Alaska Communities: A Multilevel Framework for Exploring Impacts on Individuals, Families, and Communities // Journal of Interpersonal Violence. 2008. Vol. 23, Issue 3. P. 316-338. DOI: 10.1177/0886260507312290

22. Brown N. R., Lee P. J., Krslak M., Conrad F. G., Hansen T. G. B., Havelka J., Reddon J. R. Living in History. How War, Terrorism, and Natural Disaster Affect the Organization of Autobiographical Memory // Psychological Science. 2009. Vol. 20, Issue 4. P. 399-405. DOI: 10.1111/j.1467-9280.2009.02307.x

23. Peetz J., Gunn G. R., Wilson A. E. Crimes of the Past: Defensive Temporal Distancing in the Face of Past in-Group Wrongdoing // Personality and Social Psychology Bulletin. 2010. Vol. 36, Issue 5. P. 598-611. DOI: $10.1177 / 0146167210364850$

24. Rimé B., Bouchat P., Klein O., Licata L. When collective memories of victimhood fade: Generational evolution of intergroup attitudes and political aspirations in Belgium // European Journal of Social Psychology. 2015. Vol. 45, Issue 4. P. 515-532. DOI: 10.1002/ejsp.2104

25. Gongaware T. B. Collective Memories and Collective Identities // Journal of Contemporary Ethnography. 2003. Vol. 32, Issue 5. P. 483-520. DOI: $10.1177 / 0891241603255674$

26. Sahdra B., Ross M. Group Identification and Historical Memory // Personality and Social Psychology Bulletin. 2007. Vol. 33, Issue 3. P. 384-395. DOI: $\underline{10.1177 / 0146167206296103}$

27. Rotella K. N., Richeson J. A. Motivated to "Forget": The Effects of InGroup Wrongdoing on Memory and Collective Guilt // Social Psychological and Personality Science. 2013. Vol. 4, Issue 6. P. 730-737. DOI: $10.1177 / 1948550613482986$

28. Хальбвакс М. Социальные рамки памяти. М.: Новое издательство, 2007. 348 c.

29. Weldon M. S., Bellinger K. D. Collective Memory: Collaborative and individual processes in remembering // Journal of Experimental Psychology: Learning, Memory, and Cognition. 1997. Vol. 23 (5). P. 1160-1175. DOI: $10.1037 / 0278-$ $\underline{7393.23 .5 .1160}$ 
30. Janssen S. M. J., Murre J. M. J. Reminiscence Bump in Autobiographical Memory: Unexplained by Novelty, Emotionality, Valence, or Importance of Personal Events // Quarterly Journal of Experimental Psychology. 2008. Vol. 61, Issue 12. P. 1847-1860. DOI: $10.1080 / 17470210701774242$

31. Нуркова В. В. История как личный опыт // Историческая психология и социология истории. 2009. Т. 2, № 1. С. 5-27.

32. Хальбвакс М. Коллективная и историческая память // Неприкосновенный запас. 2005. T. 40-41, № 2-3. URL: http://magazines.russ.ru/nz/2005/2/ha2. html (дата обращения: 14.08.2018).

33. Brown N. R., Lee P. J. Public events and the organization of autobiographical memory: An overview of the living-in-history project // Behavioral Sciences of Terrorism and Political Aggression. 2010. Vol. 2, Issue 2. P. 133-149. DOI: 10.1080/19434471003597431

34. Svob C., Brown N. R. Intergenerational Transmission of the Reminiscence Bump and Biographical Conflict Knowledge // Psychological Science. 2012. Vol. 23, Issue 11. P. 1404-1409. DOI: $10.1177 / 0956797612445316$

35. Емельянова Т. П., Паттисон А. С. Особенности социальных представлений о русских у жителей Чехии и США // Психологические исследования: электронный научный журнал. 2010. № 5 (13). URL: http://psystudy.ru/ num/2010n5-13/379-emelyanova-pattison13 (дата обращения: 14.08.2018).

36. Малышева Н. Г., Стефаненко Т. Г., Тихомандрицкая О. А. Образ России в многополярном мире: кросс-культурный анализ // Вестник Московского университета. Серия 14. Психология. 2012. № 1. С. 61-73.

37. Возрастная психология: учеб. пособие для студ. учреждений высш. образования / под. ред. Т. Д. Марцинковской. 2-е изд., испр. М.: Издательский центр «Академия», 2014. 336 с.

38. Пищик В. И. Поколения: социально-психологический анализ ментальности // Социальная психология и общество. 2011. № 2. С. 80-88.

39. Шестопал Е. Б. Политическая социализация и ресоциализация в современной России // Полития: Анализ. Хроника. Прогноз. 2005. № 4. URL: http://politeia.ru/content/arhiv-zhurnala/4-2005/ (дата обращения: 14.08.2018).

\section{References}

1. Arnautova Yu. A. The culture of remembrance and the history of memory. In: Repina L. P. (ed.) Istoriya i pamyat': Istoricheskaya kul'tura Evropy do nachala Novogo vremeni [History and memory: Historical culture of Europe before the modern age]. Moscow, Krug" Publ., 2006, pp. 47-55.

2. Trubina E. Learning to remember: Vectors of memory studies. In: V. N. Yarskaya, E. R. Yarskaya-Smirnova (eds.) Vlast' vremeni: sotsial'nye granitsy 
pamyati [The power of time: Social boundaries of memory]. Moscow, Variant Publ., 2011, pp. 25-44. Available at: https://www.hse.ru/pubs/share/direct/ document/69748208 (Accessed 14 August 2018).

3. Nora P. Places of memory. In: Frantsiya-pamyat' [France-Memory]. St. Petersburg, St. Petersburg University Publ., 1999, pp. 17-50.

4. Savel'eva I. M., Poletaev A. V. Historical memory: On the boundaries of the concept. In: Fenomen proshlogo [Phenomenon of the past]. Moscow, Higher School of Economics Publ., 2005, pp. 170-220.

5. Zerubavel E. Dynamics of collective memory. In: Imperiya i natsiya v zerkale istoricheskoi pamyati: sbornik statei [Empire and nation in the mirror of historical memory]. Moscow, Novoe izdatel'stvo Publ., 2011, pp. 10-29.

6. Olik D. Figurations of memory: a process-relational methodology illustrated on the German case. Sotsiologicheskoe obozrenie - Sociological Review, 2012, V. 11, no. 1, pp. 40-74. (in Russian). Available at: https://sociologica.hse.ru/ data/2012/06/05/1252356367/11_1_03.pdf (Accessed 14 August 2018).

7. Yarskaya V. Time inversion as a mechanism of memory in the context of culture. In:V. N. Yarskaya, E. R. Yarskaya-Smirnova (eds.) Vlast'vremeni: sotsial'nye granitsy pamyati [The power of time: Social boundaries of memory]. Moscow, Variant Publ., 2011, pp. 11-24. Available at:https://www.hse.ru/pubs/share/ direct/document/69748208 (Accessed 14 August 2018).

8. Assman J. Cultural memory and early civilization: Writing, remembrance, and political imagination. Cambridge, Cambridge University Press, 2011. 332 p. (Russ. ed.: Assman Ya. Kul'turnaya pamyat'. Pis'mo, pamyat'o proshlom i politicheskaya identichnost'v vysokikh kul'turakh drevnosti. Moscow, Yazyki slavyanskoi kul'tury Publ., 2004. 368 p.).

9. Ricoeur P. Memory, history, forgetting. Chicago, University of Chicago Press, 2004 (Russ. ed.: Riker P. Pamyat', istoriya, zabvenie. Moscow, Izdatel'stvo gumanitarnoi literatury Publ., 2004. 728 p.).

10. Assmann A. The new discontent with memorial culture (Russ. ed.: Assman A. Novoe nedovol'stvo memorial'noi kul'turoi. Moscow, Novoe literaturnoe obozrenie Publ., 2016. 232 p.).

11. Middleton D., Brown S. D. Issues in the socio-cultural study of memory. In: The Cambridge handbook of sociocultural psychology. Cambridge, Cambridge University Press, 2007, pp. 661-677. DOI: 10.1017/CBO9780511611162.036

12. Hirst W., Manier D. Towards a psychology of collective memory. Memory, 2008, V. 16, Issue 3, pp. 183-200. DOI: 10.1080/09658210701811912

13. Repina L. P. Memory and historiography. In: Repina L. P. (ed.) Istoriya i pamyat': Istoricheskaya kul'tura Evropy do nachala Novogo vremeni [History and memory: Historical culture of Europe before the modern age]. Moscow, Krug" Publ., 2006, pp. 19-47. 
14. Lubbe G. Historical identity. Voprosy filosofii, 1994, no. 4, pp. 108-113 (in Russian).

15. Emel'yanova T. P. Konstruirovanie sotsial'nykh predstavlenii v usloviyakh transformatsii rossiiskogo obshchestva [Constructing social representations in the conditions of transformation of Russian society]. Moscow, Institute of Psychology RAS Publ., 2006. 400 p.

16. Emel'yanova T. P. Konstruirovanie sotsial'nykh predstavlenii v usloviyakh transformatsii rossiiskogo obshchestva [Social representations: History, theory and empirical research]. Moscow, Institute of Psychology RAS Publ., 2016. 476 p.

17. Kuznetsova A. V. Collective memories of political power in various historical periods in representatives of different social groups of Russians. Sotsial'naya psikhologiya i obshchestvo - Social Psychology and Society, 2013, no. 3, pp. 102-115 (in Russian).

18. Petrenko E., Kozhevina E., Kaplun V. Russia: The end of the 20th century: Representations of our contemporaries. In: V. N. Yarskaya, E. R. YarskayaSmirnova (eds.) Vlast' vremeni: sotsial'nye granitsy pamyati [The power of time: Social boundaries of memory]. Moscow, Variant Publ., 2011, pp. 11-24. Available at: https://www.hse.ru/pubs/share/direct/document/69748208 (Accessed 14 August 2018).

19. Dontsov A. I., Goncharova V. A. The Holocaust as a phenomenon of social memory. Vek tolerantnosti: nauchno-publitsisticheskii vestnik - Age of Tolerance: Scientific-Publicistic Bulletin, 2005, no. 1-2, pp. 55-61 (in Russian).

20. Gorenshtein N. I. Perception of Holocaust events by modern day youth. Rossiiskii psikhologicheskii zhurnal - Russian Psychological Journal, 2016, V. 13, no. 1, pp. 191-199 (in Russian).

21. Evans-Campbell T. Historical trauma in American Indian/Native Alaska communities: A multilevel framework for exploring impacts on individuals, families, and communities. Journal of Interpersonal Violence, 2008, V. 23, Issue 3, pp. 316-338. DOI: 10.1177/0886260507312290

22. Brown N. R., Lee P. J., Krslak M., Conrad F. G., Hansen T. G. B., Havelka J., Reddon J. R. Living in History. How war, terrorism, and natural disaster affect the organization of autobiographical memory. Psychological Science, 2009, V. 20, Issue 4, pp. 399-405. DOI: 10.1111/j.1467-9280.2009.02307.x

23. Peetz J., Gunn G. R., Wilson A. E. Crimes of the past: Defensive temporal distancing in the face of past in-group wrongdoing. Personality and Social Psychology Bulletin, 2010, V. 36, Issue 5, pp. 598-611. DOI: $10.1177 / 0146167210364850$

24. Rimé B., Bouchat P., Klein O., Licata L. When collective memories of victimhood fade: Generational evolution of intergroup attitudes and political aspirations in Belgium. European Journal of Social Psychology, 2015, V. 45, Issue 4, pp. 515-532. DOI: 10.1002/ejsp.2104 


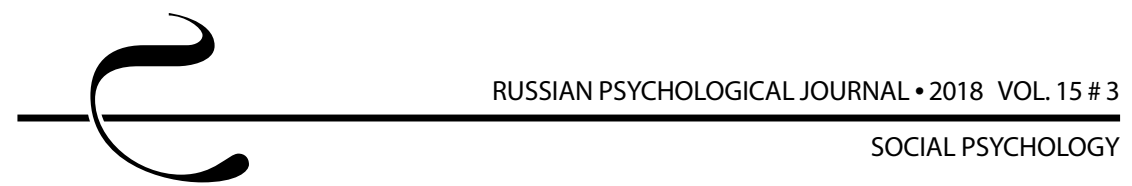

25. Gongaware T. B. Collective memories and collective identities. Journal of Contemporary Ethnography, 2003, V. 32, Issue 5, pp. 483-520. DOI: 10.1177/0891241603255674

26. Sahdra B., Ross M. Group identification and historical memory. Personality and Social Psychology Bulletin, 2007, V. 33, Issue 3, pp. 384-395. DOI: 10.1177/0146167206296103

27. Rotella K. N., Richeson J. A. Motivated to "forget": The effects of in-group wrongdoing on memory and collective guilt. Social Psychological and Personality Science, 2013, V. 4, Issue 6, pp. 730-737. DOI: 10.1177/1948550613482986

28. Halbwachs M. The social frameworks of memory (Russ. ed.: Khal'bvaks M. Sotsial'nye ramki pamyati. Moscow, Novoe izdatel'stvo Publ., 2007. 348 p.).

29. Weldon M. S., Bellinger K. D. Collective memory: Collaborative and individual processes in remembering. Journal of Experimental Psychology: Learning, Memory, and Cognition, 1997, V. 23 (5), pp. 1160-1175. DOI: 10.1037/02787393.23.5.1160

30. Janssen S. M. J., Murre J. M. J. Reminiscence bump in autobiographical memory: Unexplained by novelty, emotionality, valence, or importance of personal events. Quarterly Journal of Experimental Psychology, 2008, V. 61, Issue 12, pp. 1847-1860. DOI: 10.1080/17470210701774242

31. Nurkova V. V. History as personal experience. Istoricheskaya psikhologiya i sotsiologiya istorii - Historical Psychology \& Sociology, 2009, V. 2, no. 1, pp. 5-27 (in Russian).

32. Halbwachs M. Collective and historical memory. Neprikosnovennyi zapas, 2005, V. 40-41, no. 2-3 (in Russian). Available at: http://magazines.russ.ru/ nz/2005/2/ha2.html (Accessed 14 August 2018).

33. Brown N. R., Lee P. J. Public events and the organization of autobiographical memory: An overview of the living-in-history project. Behavioral Sciences of Terrorism and Political Aggression, 2010, V. 2, Issue 2, pp. 133-149. DOI: 10.1080/19434471003597431

34. Svob C., Brown N. R. Intergenerational transmission of the reminiscence bump and biographical conflict knowledge. Psychological Science, 2012, V. 23, Issue 11, pp. 1404-1409. DOI: 10.1177/0956797612445316

35. Emelyanova T. P., Pattison A. S. Peculiarities of social representations of Russians in Czechs and Americans. Psychological Studies, 2010, no. 5 (13) (in Russian). Available at: http://psystudy.ru/num/2010n5-13/379-emelyanovapattison13 (Accessed 14 August 2018).

36. Malysheva N. G., Stefanenko T. G., Tikhomandritskaya O. A. Image of Russia in the multipolar world: Cross-cultural analysis. Vestnik Moskovskogo universiteta. Seriya 14. Psikhologiya - Moscow University Psychology Bulletin. Series 14. Psychology, 2012, no. 1, pp. 61-73 (in Russian). 
37. Martsinkovskaya T. D. (ed.) Vozrastnaya psikhologiya [Age psychology]. Moscow, Akademiya Publ., 2014. 336 p.

38. Pishchik V. I. Generations: Socio-psychological analysis of mentality. Sotsial'naya psikhologiya i obshchestvo - Social Psychology and Society, 2011, no. 2, pp. 80-88 (in Russian).

39. Shestopal E. B. Political socialization and resocialization in modern Russia. Politiya:Analiz. Khronika. Prognoz - Polity:Analysis. Chronicle. Forecast, 2005, no. 4 (in Russian). Available at: http://politeia.ru/content/arhiv-zhurnala/4-2005/ (Accessed 14 August 2018). 